Mehmet Bozca

Machine Design Division, Mechanical Engineering Faculty, Yildiz Technical University, Turkey, Istanbul, 34349 Yildiz, E-mail: mbozca@yildiz.edu.tr

\title{
INVESTIGATION OF THE EFFECTIVE PARAMETERS OF SCUFFING FAILURE IN GEARS
}

Received: June 24, 2020 / Revised: July 30, 2020 / Accepted: July 31, 2020

(C) Bozca M., 2020

\begin{abstract}
This study investigates the effective parameters of scuffing failure in gears using the integral temperature method. For this aim, the mass temperature, integral temperature and scuffing safety factor are calculated for a given parameters. Then, integral temperatures are simulated based on various geometrical, operational and lubrication parameters. Obtained results are presented graphically. The obtained results show that increasing the module $m_{n}$ results in a decrease in the integral temperature $\vartheta_{\text {int }}$. Similarly, increasing the pinion teeth number $z_{p}$ results in a decrease in the integral temperature $\vartheta_{\text {int }}$. Increasing the module and tooth number positively affects the scuffing failure in gears. In contrast, increasing the transmitted torque $M_{T I T}$ results in an increase in the integral temperature $\vartheta_{\text {int }}$. Similarly, increasing the pinion speed $n_{p}$ increases the mass temperature $\vartheta_{M}$, and increasing the lubricant (oil) $\vartheta_{\ddot{O}}$ temperature increases the integral temperature $\vartheta_{\text {int }}$. Increasing the transmitted torque, lubricant temperature and the pinion speed negatively affects the scuffing failure in gears. Finally, increasing the nominal kinematic viscosity $v_{40}$ decreases the integral temperature $\vartheta_{\text {int }}$. Increasing the nominal kinematic viscosity positively affects the scuffing failure in gears. By considering the effective parameters of scuffing failure such as geometrical, operational and lubrication, one can design and manufacture the desired gears without scuffing failure.
\end{abstract}

Keywords: gear failure, scuffing, kinematic viscosity, mass temperature, integral temperature.

\section{Introduction}

Gears are widely used to mechanically transmit power in rotating machines and in the vehicle industry. Engineers always aim to design and manufacture high-strength gears to safely transmit the required power without failure.

Gear failures are classified into tooth breakages as a result of tooth bending stress, surface pitting as a result of tooth contact stress and scuffing as a result of high temperature and high contact stress. Gear failures can be prevented by considering these potential failure conditions.

Gears are designed by considering the potential failure mechanism, and different standards were developed by organizations such as ISO, DIN and AGMA. The following information on scuffing failure in gears can be found in the literature:

- the lubricant (oil) temperature, lubricant (oil) level and surface roughness are considered effective parameters for scuffing failure phenomena in gears. The effect of the oil temperature on gear failure in experiments is presented. The thickness of the protective elastohydrodynamic lubricant film depends on the lubricant viscosity at the operating temperature. Thus, high temperatures lead to the formation of a lowviscosity and thin oil film, high chemical activity and good tribological layer formation [1];

- lubricant (oil) level is considered an effective parameter for scuffing failure phenomena in gears. The influence of the immersion depth of dip-lubricated gears on the power loss, bulk temperature and scuffing capacity is experimentally and numerically studied. It is concluded that the occurrence of the gear scuffing failure mode is strongly determined by the lubricant (oil) levels [2].

Surface roughness is considered an effective parameter for scuffing failure phenomena in gears. A surface coating is applied to provide the required surface quality and low friction on gears. The effect of low-friction coatings on the scuffing load capacity and efficiency of gears is presented. Surface coatings 


\section{Mehmet Bozca}

can reduce the friction coefficient between gear teeth by $8-41 \%$ depending on the operating speed and coating type. Coated gears improve the efficiency of a gearbox in low-speed, high-torque conditions [3].

The gear material, heat treatment and surface (contact) pressure are also effective parameters for scuffing failure phenomena. Scuffing risk to spur and helical gears in commercial vehicle transmissions is predicted by the flash temperature method. It is concluded that when the maximum contact temperature is close to or above the limiting scuffing temperature for the combination of lubricant and gear material, scuffing likely occurs [4].

Surface finishing is also an effective parameter to provide the required lubrication condition for scuffing failure phenomena. To reduce the risk of scuffing, isotropic superfinishing is presented. It is concluded that decreasing the surface roughness, particularly through isotropic superfinishing, significantly increases the scuffing resistance because of the increased lubricant film thickness and decreased friction [5].

The effective parameters of scuffing failure in gears are investigated using the integral temperature method, which is defined by ISO 6336 and DIN 3990 standards.

By varying geometrical parameters such as the module and number of teeth, the relationship between the module and integral temperature and the relationship between the number of teeth and integral temperature relation are graphically presented. Similarly, by varying the operational parameters such as the transmitted torque and pinion speed, the relationship between torque and integral temperature is graphically presented. By considering the lubrication (oil) parameters, the relationship between lubricant (oil) temperature and integral temperature and the relationship between the nominal viscosity of the oil and the integral temperature are graphically presented.

\section{Problem Statement}

A particularly severe form of gear tooth surface failure occurs when areas of tooth surfaces seize or are welded together due to the absence or breakdown of the lubricant film between the contacting tooth flanks of the mating gears, which is caused by high temperature and high pressure. This form of failure is termed "scuffing" and is most relevant when the surface velocities are high. Scuffing failure may also occur at relatively low sliding velocities when the tooth surface pressures are sufficiently high. A scuffed gear surface feature has a matte appearance, as shown in Fig. 1.

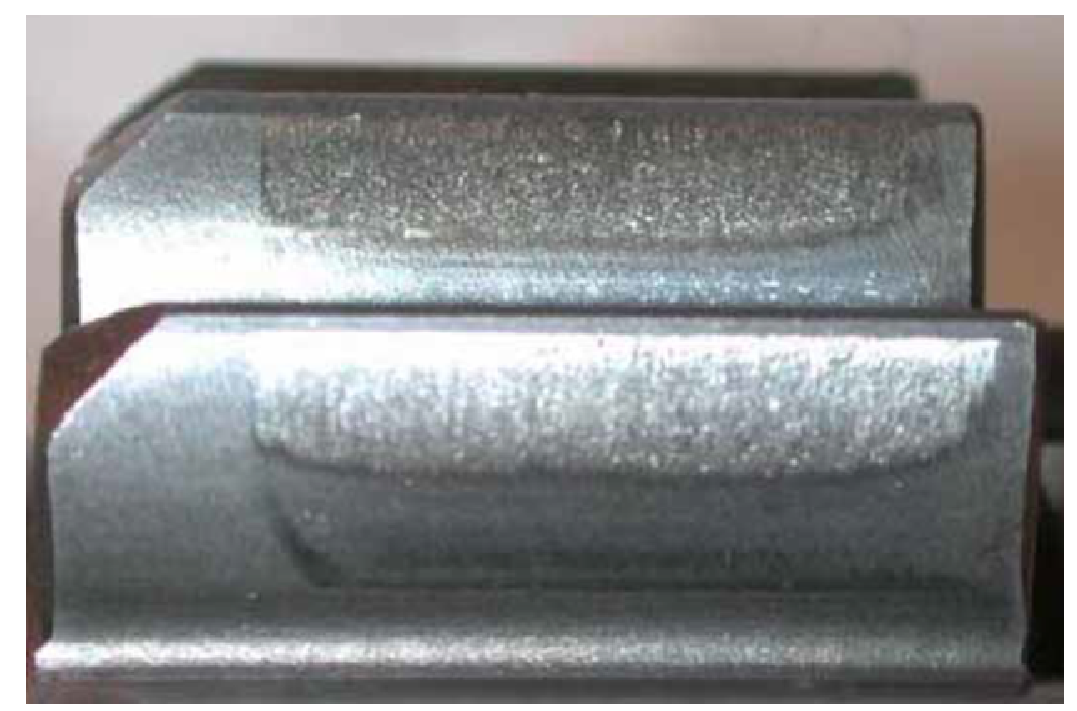

Fig. 1. Scuffed gear surface [5]

\section{Methodology}

The integral temperature criterion to evaluate the probability of scuffing is based on the assumption that scuffing likely occurs when the mean contact temperature along the path of contact is equal to or exceeds the corresponding "permissible integral temperature".

In the integral temperature method, the sum of the bulk temperature and the weighted mean of the integrated values of flash temperatures along the path of contact is the "integral temperature". 
The probability of scuffing is assessed by comparing the integral temperature with a corresponding "permissible integral temperature", which is derived from the gear testing of lubricants for the scuffing resistance or from gears that have scuffed in service.

The integral temperature $\vartheta_{\text {int }}$ is calculated as follows [6]-[9]:

$$
\vartheta_{\text {int }}=\vartheta_{M}+C_{2} \cdot \vartheta_{\text {flaint }} \leq \vartheta_{\text {int } P}
$$

where $\vartheta_{\mathrm{M}}\left[{ }^{\circ} \mathrm{C}\right]$ is the mass temperature of the tooth surface immediately before the intervention; $C_{2}$ is the weighting factor from experiments, and we assume that $C_{2}=1.5 ; \vartheta_{\text {flaint }}\left[{ }^{\circ} \mathrm{C}\right]$ is the average flash temperature; and $\vartheta_{\text {intP }}\left[{ }^{\circ} \mathrm{C}\right]$ is the permissible integral temperature.

Mass temperature $\vartheta_{\mathrm{M}}\left[{ }^{\circ} \mathrm{C}\right]$ is calculated as follows [6]-[9]:

$$
\vartheta_{M}=X_{S} \cdot\left(\vartheta_{\ddot{O}}+C_{1} \cdot \vartheta_{\text {flaint }}\right) \text {, }
$$

where $X_{S}$ is the lubrication factor and we assume that $X_{S}=1$ for splash lubrication, $X_{S}=1.2$ for injection lubrication, and $X_{S}=0.2$ for gear wheels that completely run in oil; $\vartheta_{\ddot{O}}\left[{ }^{\circ} \mathrm{C}\right]$ is the lubricating oil temperature before tooth engagement; $C_{1}$ is the weighting factor from experiments, and we assume that $C_{1}=0.7 ;$ and $\vartheta_{\text {flaint }}\left[{ }^{\circ} \mathrm{C}\right]$ is the average flash temperature.

The average flash temperature $\vartheta_{\text {flaint }}$ is calculated as follows [6]-[9]:

$$
\vartheta_{\text {flaint }}=\vartheta_{f l a E} . X_{\varepsilon} \text {, }
$$

where $\vartheta_{f l a E}\left[{ }^{\circ} \mathrm{C}\right]$ is the flash temperature at head engagement point $E$ of the pinion; and $X_{\varepsilon}$ is the contact ratio factor.

The flash temperature at the head engagement point $E$ of the pinion $\vartheta_{f l a E}\left[{ }^{\circ} \mathrm{C}\right]$ is calculated as follows [6]-[9]:

$$
\vartheta_{f l a E}=K \cdot \mu_{m c} \cdot \frac{w_{n}\left|v_{t 1}-v_{t 2}\right|}{\sqrt{2 \cdot b_{h}} \cdot\left(B_{M 1} \cdot \sqrt{v_{t 1}}+B_{M 2} \cdot \sqrt{v_{t 2}}\right)},
$$

where $K$ is the empirical factor $K=1.11 ; \mu_{m C}$ is the average coefficient of friction; $w_{n}[\mathrm{~N} / \mathrm{mm}]$ is the line load in the normal direction; $v_{t 1,2}[\mathrm{~m} / \mathrm{s}]$ are the tangential velocities of radii 1 and $2 ; b_{h}$ is the face width; and $B_{M 1,2}$ are the thermal contact coefficients of radii 1 and 2 .

The permissible integral temperature $\vartheta_{\text {intP }}$ is calculated as follows [6]-[9]:

$$
\vartheta_{\text {int } P}=\frac{\vartheta_{\text {int } S}}{S_{S \min }}
$$

with

$$
\vartheta_{\text {int } S} \approx \vartheta_{M T}+X_{W r e l T} . C_{2} \cdot \vartheta_{\text {flaint } T},
$$

where $\vartheta_{M T}\left[{ }^{\circ} \mathrm{C}\right]$ is the mass temperature as a function of the pinion torque; $X_{W r e l T}$ is the relative structure factor; $\vartheta_{\text {flaint } T}\left[{ }^{\circ} \mathrm{C}\right]$ is the average flash temperature, index $T$ denotes the test values during the scuffing test run in the test bench; and $S_{S \min }$ is the minimum scuffing safety factor.

The mass temperature $\vartheta_{M T}$ and the average flash temperature $\vartheta_{f l a i n t T}$ during the scuffing test run in the test bench are calculated as follows [6]-[9]:

$$
\vartheta_{M T}=80+0.23 \cdot M_{T 1 T}
$$

and

$$
\vartheta_{\text {flaint } T}=0,08 \cdot M_{T 1 T}^{1,2} \cdot\left(\frac{100}{v_{40}}\right)^{v_{40}^{-0.4}},
$$

where $M_{T 1 T}[\mathrm{~N} \cdot \mathrm{m}]$ is the pinion torque; and $v_{40}$ is the nominal kinematic viscosity.

The computational scuffing safety factor $S_{\text {ints }}$ with the integral temperature process is calculated as follows [6]-[9]:

$$
S_{\text {int } S}=\frac{\vartheta_{\text {int } S}}{\vartheta_{\text {int }}} \geq S_{S \min }
$$




\section{Mehmet Bozca}

The following three conditions are true for scuffing failure phenomena:

- if $S_{\text {int } S}>1.0$ : scuffing failure does not occur in the gears;

- if $S_{\text {int } S}=1.0$ : scuffing failure limit;

- if $S_{\text {int } S}<1.0$ : scuffing failure occurs in the gears.

\section{Numerical Example}

In the numerical study, the relationship between the effective parameters and the integral temperature are simulated based on the assumed geometrical, operational and lubrication parameters. The geometrical parameters such as module $m_{n}$, number of teeth $z$, and face width $b_{h}$ are shown in Table 1.

Table 1

\section{Geometrical parameters}

\begin{tabular}{|c|c|c|}
\hline Geometrical parameters & Unit & Value \\
\hline Normal module $m_{n}$ & {$[\mathrm{~mm}]$} & 9 \\
\hline Number of pinion teeth $z_{1}$ & {$[-]$} & 17 \\
\hline Face width $b_{h}$ & {$[\mathrm{~mm}]$} & 60 \\
\hline
\end{tabular}

Operational parameters such as transmitted power $P$, pinion speed $n_{p}$ and scuffing torque (or transmitted torque) $M_{T 1 T}$ are shown in Table 2.

Table 2

Operational parameters

\begin{tabular}{|c|c|c|}
\hline Operational parameters & Unit & Value \\
\hline Transmitted power $P$ & {$[\mathrm{~kW}]$} & 410 \\
\hline Pinion speed $n_{p}$ & {$\left[\mathrm{~min}^{-1}\right]$} & 1300 \\
\hline Scuffing torque $M_{T 1 T}$ & {$[\mathrm{~N} \cdot \mathrm{m}]$} & 372 \\
\hline
\end{tabular}

Lubrication parameters such as oil temperature $\vartheta_{\ddot{O}}$, lubricant kinematic viscosity $v_{40}$, lubrication factor $X_{S}$, and friction coefficient $\mu$ are shown in Table 3 .

Table 3

Lubrication parameters

\begin{tabular}{|c|c|c|}
\hline Lubrication parameters & Unit & Value \\
\hline Oil temperature & {$\left[{ }^{\circ} \mathrm{C}\right]$} & 100 \\
\hline Lubricant kinematic viscosity at $40^{\circ} \mathrm{C} v_{40}$ & {$\left[\mathrm{~mm}^{2} / \mathrm{s}\right]$} & 220 \\
\hline Lubrication factor $X_{S}$ & {$[-]$} & 1.0 \\
\hline Friction coefficient $\mu$ & {$[-]$} & 0.073 \\
\hline
\end{tabular}

By considering the geometrical parameters, operational parameters and lubrication parameters in Tables 1-3, the scuffing parameters are calculated and presented in Table 4.

Table 4

Scuffing parameters

\begin{tabular}{|c|c|c|}
\hline Scuffing parameters & Unit & Value \\
\hline Mass temperature $\vartheta_{M T}$ & {$\left[{ }^{\circ} \mathrm{C}\right]$} & 165.56 \\
\hline Integral temperature $\vartheta_{\text {int }}$ & {$\left[{ }^{\circ} \mathrm{C}\right]$} & 263.67 \\
\hline Permissible integral temperature $\vartheta_{\text {int } P}$ & {$\left[{ }^{\circ} \mathrm{C}\right]$} & 298.68 \\
\hline Scuffing safety factor $S_{\text {int } S}$ & {$[-]$} & 1.1328 \\
\hline
\end{tabular}

The integral temperature $\vartheta_{\text {int }}$ reached the permissible integral temperature $\vartheta_{\text {int } P \text {, so the scuffing safety }}$ factor $S_{\text {ints }}$ was equal to 1.1328 based on Equation (9), and the obtained values under safety for scuffing failure are presented in Table 4. 


\section{Simulation of the scuffing parameters}

By varying the effective parameters of scuffing failure such as the geometrical, operational and lubrication parameters, the integral temperatures are simulated.

Effect of the geometrical parameters

By varying module $m_{n}$, the change in the integral temperature $\vartheta_{\text {int }}$ is simulated as shown in Fig. 2. Increasing module $m_{n}$ results in a decrease in the integral temperature $\vartheta_{\text {int }}$.

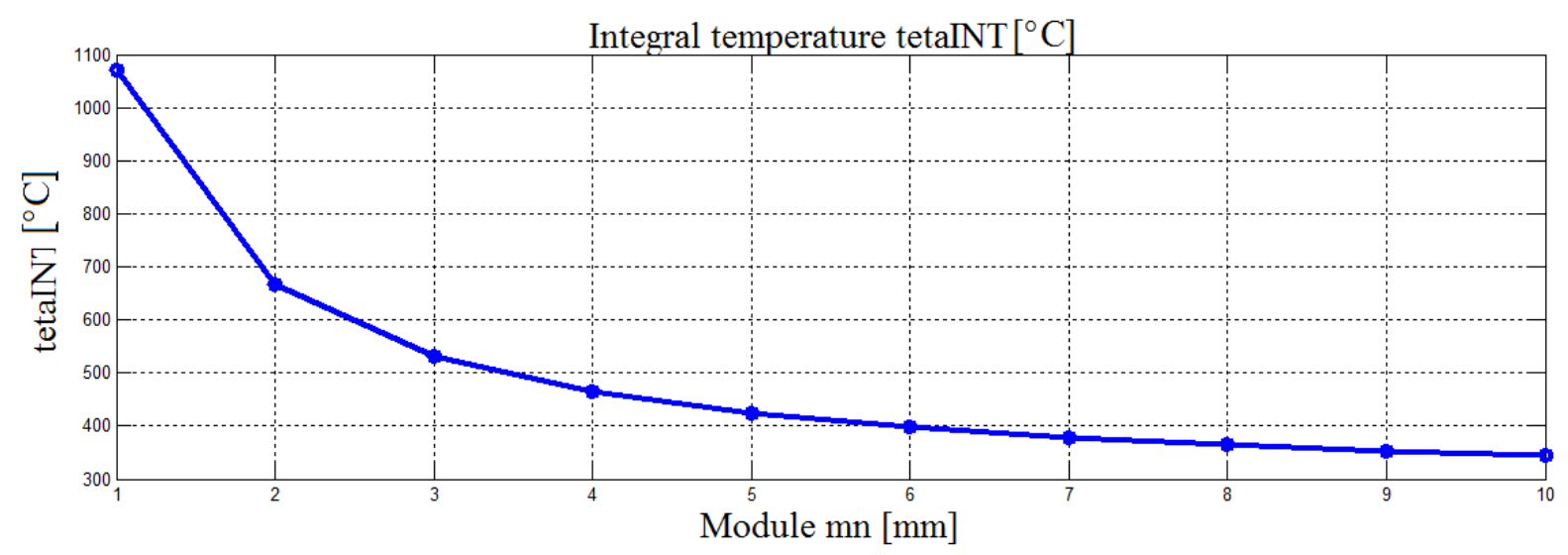

Fig. 2. Relationship between the module and integral temperature

By varying the tooth number $z_{p}$, the change in the integral temperature $\vartheta_{\text {int }}$ is simulated as shown in Fig. 3. Increasing the tooth number $z_{p}$ results in a decrease in the integral temperature $\vartheta_{\text {int. }}$.

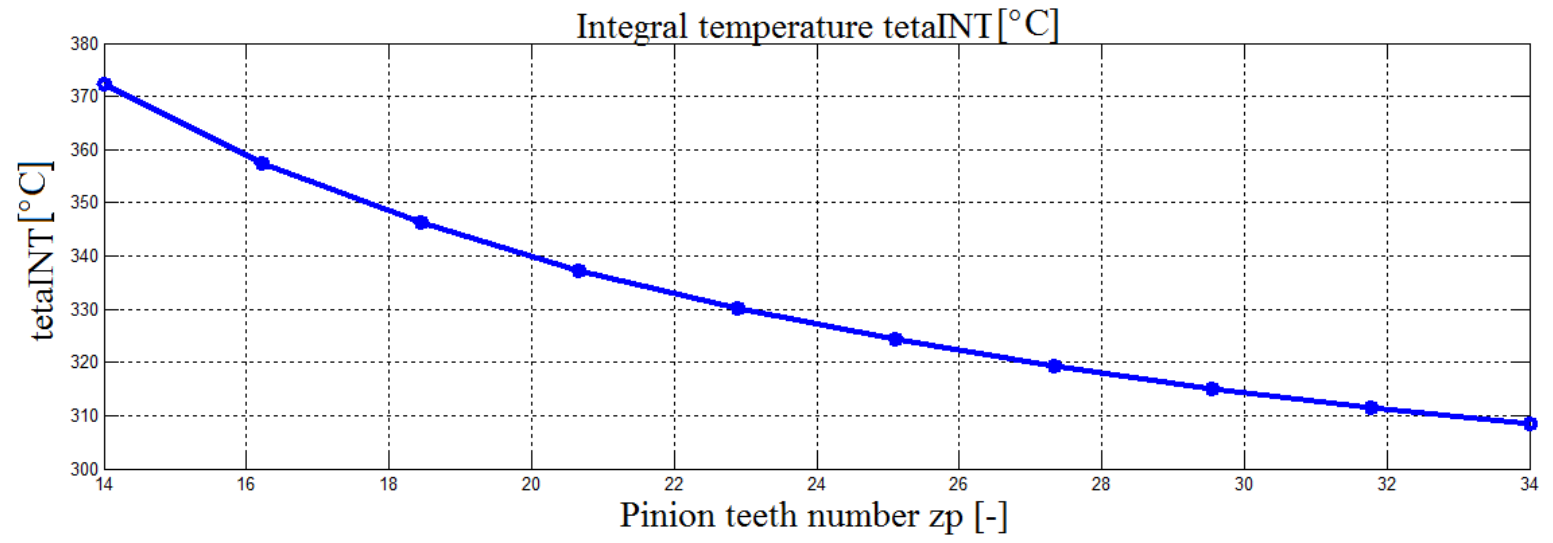

Fig. 3. Relationship between number of pinion teeth and integral temperature

By varying the transmitted torque $M_{T 1 T}$, the change in the integral temperature $\vartheta_{\text {int }}$ is simulated as shown in Fig. 4. Increasing torque $M_{T 1 T}$ results in an increase in the integral temperature $\vartheta_{\text {int }}$.

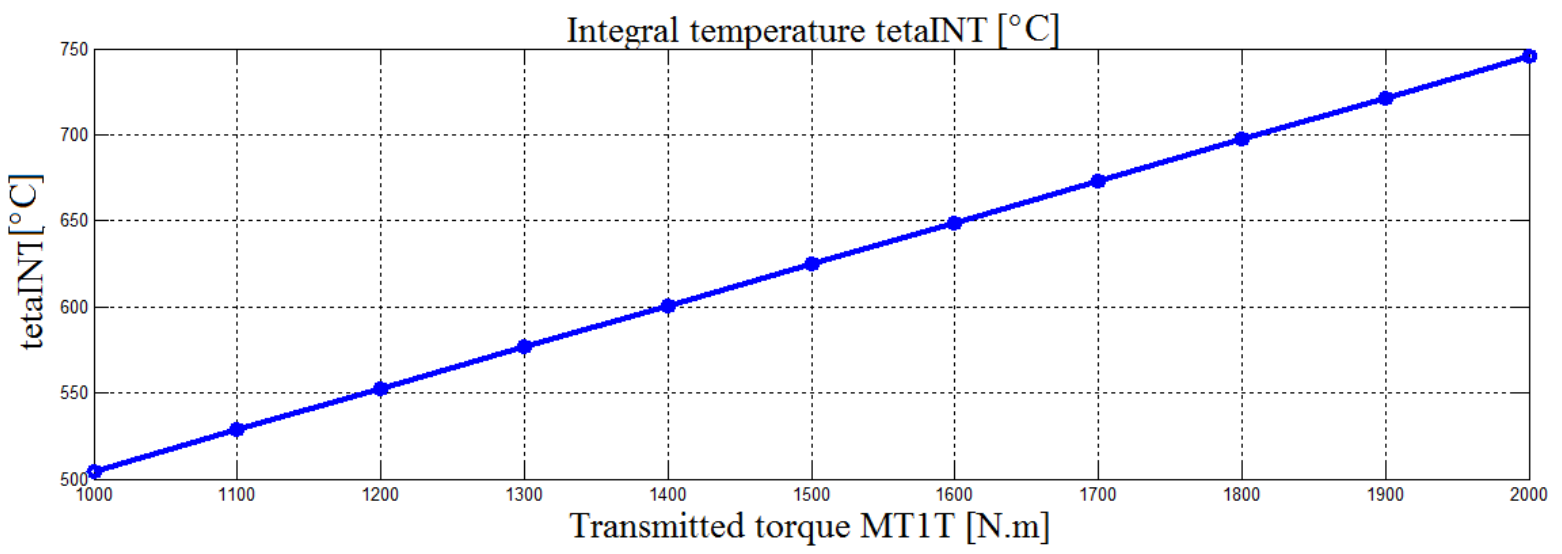

Fig. 4. Relationship between transmitted torque and scuffing integral temperature 


\section{Mehmet Bozca}

By varying the pinion speed $n_{p}$, the change in the mass temperature $\vartheta_{M}$ is simulated as shown in Fig. 5. Increasing the pinion speed $n_{p}$ results in an increase in the mass temperature $\vartheta_{M}$.

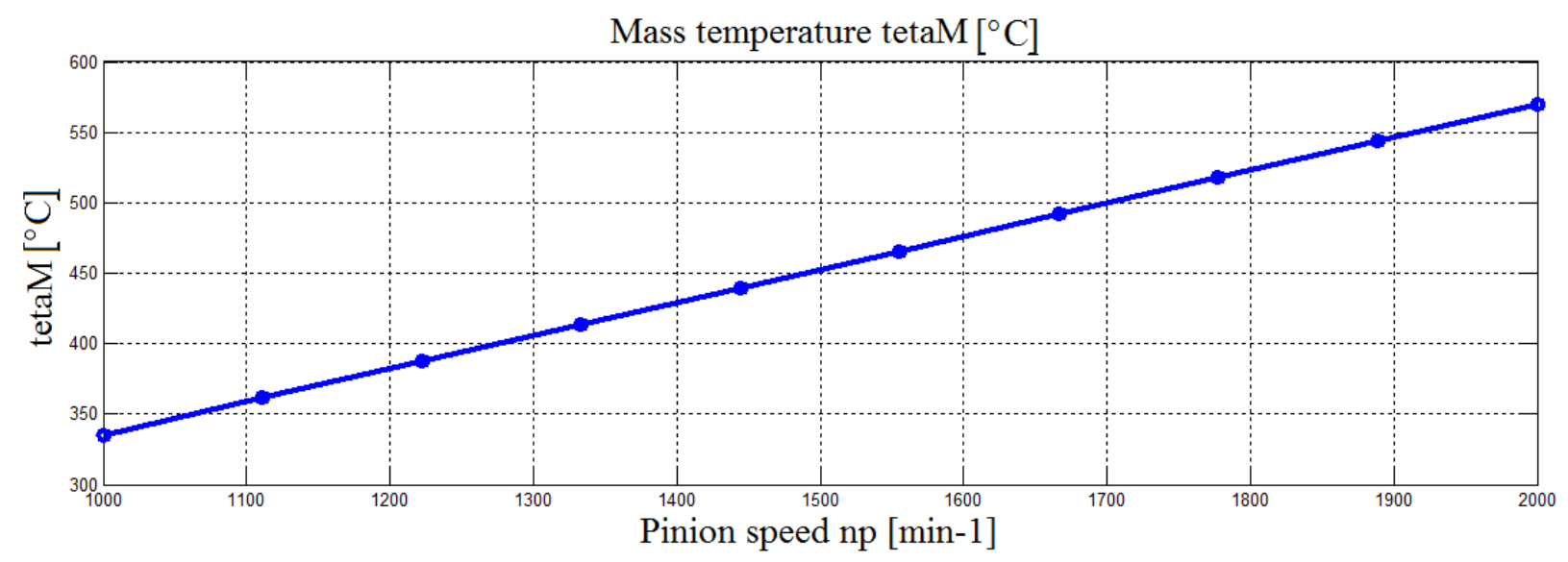

Fig. 5. Relationship between pinion speed and mass temperature

\section{Effect of the lubrication parameters}

By varying lubrication (oil) temperature $\vartheta_{\ddot{O}}$, the change in integral temperature $\vartheta_{\text {int }}$ is simulated as shown in Fig. 6. Increasing the lubricant (oil) temperature $\vartheta_{\ddot{O}}$ results in an increase in the integral temperature $\vartheta_{\text {int. }}$.

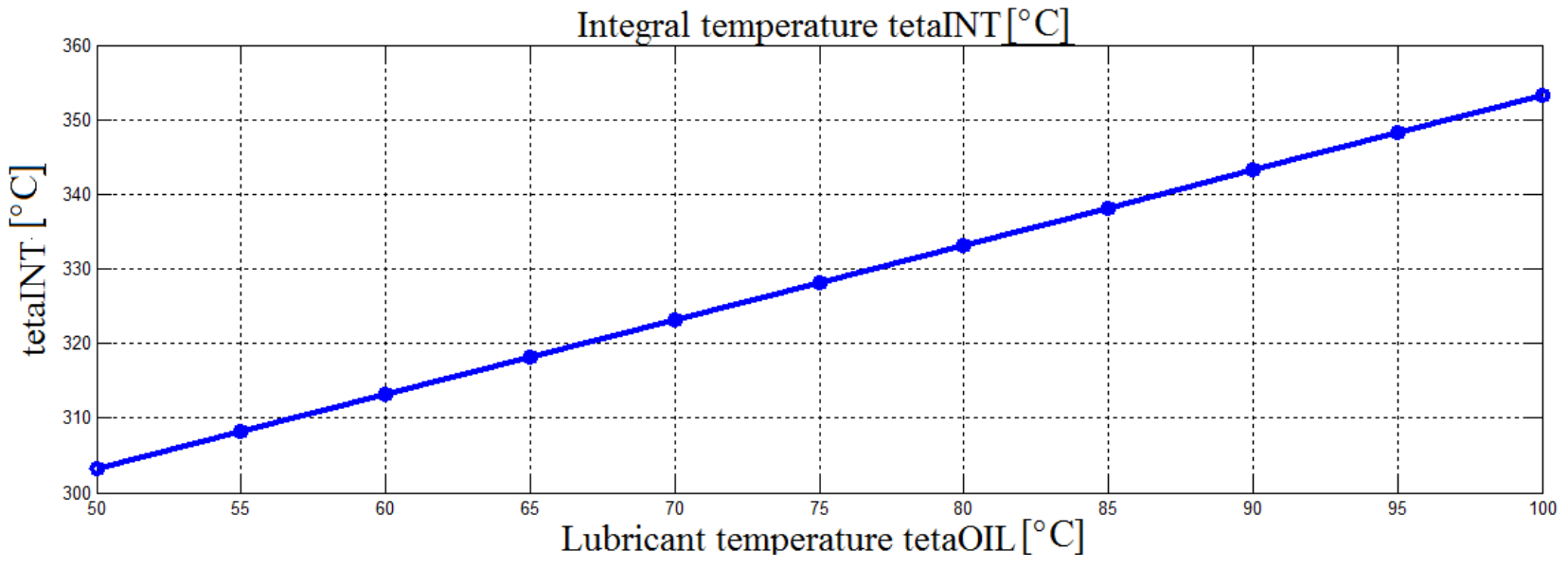

Fig. 6. Relationship between oil temperature and integral temperature

By varying the nominal viscosity $v_{40}$, the change in the integral temperature $\vartheta_{\text {int }}$ is simulated as shown in Fig. 7. Increasing nominal kinematic viscosity $v_{40}$ results in a decrease in integral temperature $\vartheta_{\text {int. }}$.

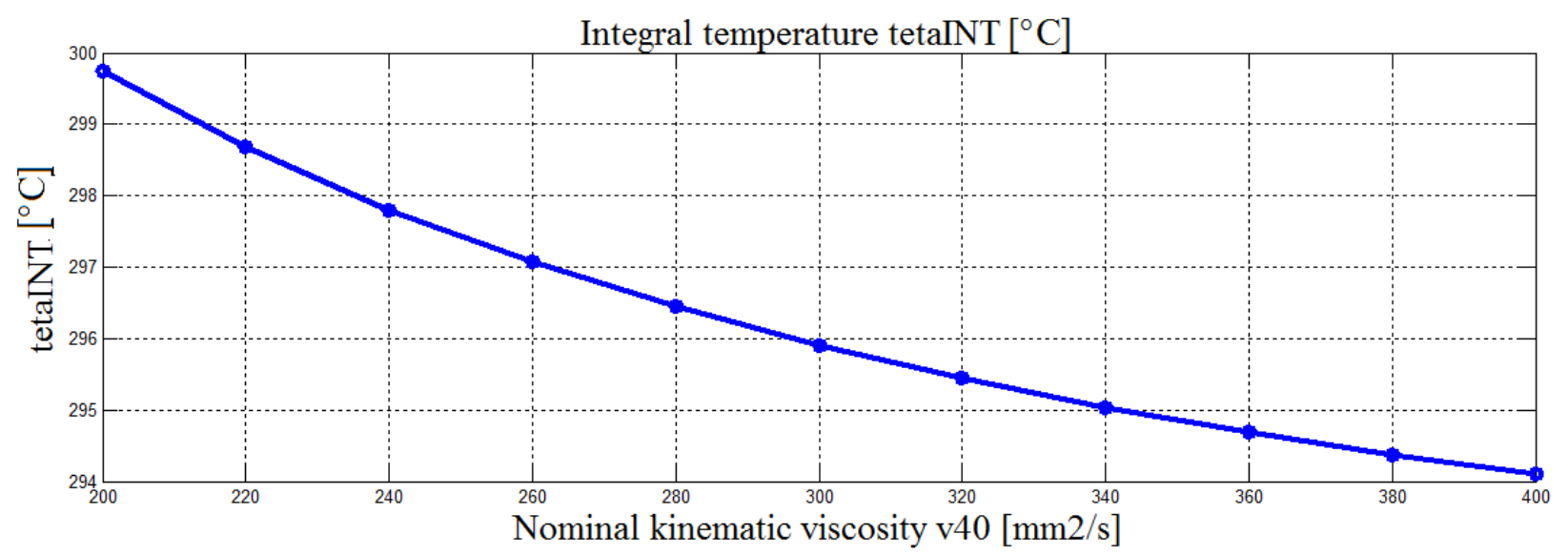

Fig. 7. Relationship between nominal kinematic viscosity and scuffing integral temperature 


\section{Results}

The increase in the module $m_{n}$ from $1 \mathrm{~mm}$ to $10 \mathrm{~mm}$ results in a decrease in the integral temperature $\vartheta_{\text {int }}$ from $1070{ }^{\circ} \mathrm{C}$ to $344{ }^{\circ} \mathrm{C}$, as presented in Fig. 2. The increase in the number of pinion teeth $z_{p}$ from 14 to 34 results in a decrease in the integral temperature $\vartheta_{\text {int }}$ from $372.40{ }^{\circ} \mathrm{C}$ to $308.39{ }^{\circ} \mathrm{C}$, as presented in Fig. 3 .

The increase in the torque $M_{T 1 T}$ from $200 \mathrm{~N} \cdot \mathrm{m}$ to $2000 \mathrm{~N} \cdot \mathrm{m}$ increases the integral temperature $\vartheta_{\text {int }}$ from $504.49{ }^{\circ} \mathrm{C}$ to $745.39{ }^{\circ} \mathrm{C}$, as shown in Fig. 4. The increase in the pinion speed $n_{p}$ from $1000 \mathrm{~min}^{-1}$ to $2000 \mathrm{~mm}^{-1}$ increases the mass temperature $\vartheta_{M}$ from $335.23{ }^{\circ} \mathrm{C}$ to $570.23{ }^{\circ} \mathrm{C}$, as presented in Fig. 5 .

The increase in the lubricant (oil) temperature $\vartheta_{\ddot{O}}$ from $50{ }^{\circ} \mathrm{C}$ to $100{ }^{\circ} \mathrm{C}$ increases the integral temperature $\vartheta_{\text {int }}$ from $303.20{ }^{\circ} \mathrm{C}$ to $353.20{ }^{\circ} \mathrm{C}$, as presented in Figure 6. Increasing the nominal kinematic viscosity $v_{40}$ from $200 \mathrm{~mm}^{2} / \mathrm{s}$ to $400 \mathrm{~mm}^{2} / \mathrm{s}$ decreases the integral temperature $\vartheta_{\text {ints }}$ from $299.73{ }^{\circ} \mathrm{C}$ to 294.09 ${ }^{\circ} \mathrm{C}$, as presented in Fig. 7.

\section{Conclusions}

Among the geometrical parameters, increasing the module $m_{n}$ strongly decreases the integral temperature $\vartheta_{\text {int }}$, and increasing the number of pinion teeth $z_{p}$ slightly decreases the integral temperature $\vartheta_{\text {int. }}$ Increasing the module and tooth number positively affects the scuffing failure in gears. Furthermore, increasing the module and tooth number positively affects the tooth bending and tooth contact failure in gears

Among the operational parameters, increasing the torque $M_{T 1 T}$ strongly increases the integral temperature $\vartheta_{\text {int }}$. Similarly, increasing the pinion speed $n_{p}$ strongly increases the mass temperature $\vartheta_{M}$. Increasing the transmitted torque, lubricant temperature and the pinion speed negatively affects the scuffing failure in gears.

Among the lubrication parameters, increasing the lubricant (oil) temperature $\vartheta_{\ddot{O}}$ strongly increases the integral temperature $\vartheta_{\text {int. }}$ In contrast, increasing the nominal kinematic viscosity $v_{40}$ slightly decreases the integral temperature $\vartheta_{\text {int. }}$ Increasing the nominal kinematic viscosity positively affects the scuffing failure in gears.

By considering the effective parameters of scuffing failure such as geometrical, operational and lubrication, one can design and manufacture the desired gears without scuffing failure.

The scuffing capacity of gears will be experimentally and statistically investigated by the author in a future study to determine the reliability level of gears.

\section{References}

[1] B. R. Höhn, and K. Michaelis, "Influence of oil temperature on gear failures", Tribology International, vol. 37, pp. 103-109, 2004.

[2] B. R. Höhn, K. Michaelis, and H.-Ph. Otto, "Influence of immersion depth of dip lubricated gears on power loss, bulk temperature and scuffing load carrying capacity", Int. J. Mech. Mater Des., vol. 4, pp. 145-156, 2008.

[3] R. Martins, R. Amaro, and J. Seabra, "Influence of low friction coatings on the scuffing load capacity and efficiency of gears", Tribology International, vol. 41, pp. 234-243, 2008.

[4] C. H. Wink, "Predicted Scuffing Risk to Spur and Helical Gears in Commercial Vehicle Transmissions", Gear Technology, pp. 82-86, November/December 2012.

[5] M. McCormick, "The risk of scuffing, a non-fatigue-based failure mode, can be reduced via isotropic superfinishing", Gear Solutions, September 2016. [Online]. Available: https://gearsolutions.com/departments/materials-matter-scuffing/. Accessed on: June 31, 2020.

[6] B. Schlecht, Maschinenelemente [Machine elements]. München, Germany: Pearson Studium, 2010. [in German].

[7] Tragfähigkeitsberechnung von Stirnrädern; Berechnung der Fresstragfähigkeit [Calculation of load capacity of cylindrical gears; calculation of scuffing load capacity], DIN 3990-4, 1987. [in German].

[8] Calculation of load capacity of spur and helical gears - Part 21: Calculation of scuffing load capacity (also applicable to bevel and hypoid gears) - Integral temperature method, ISO/TS 6336-21, 2017.

[9] Calculation of load capacity of spur and helical gears - Part 20: Calculation of scuffing load capacity (also applicable to bevel and hypoid gears) - Flash temperature method, ISO/TS 6336-20, 2017. 